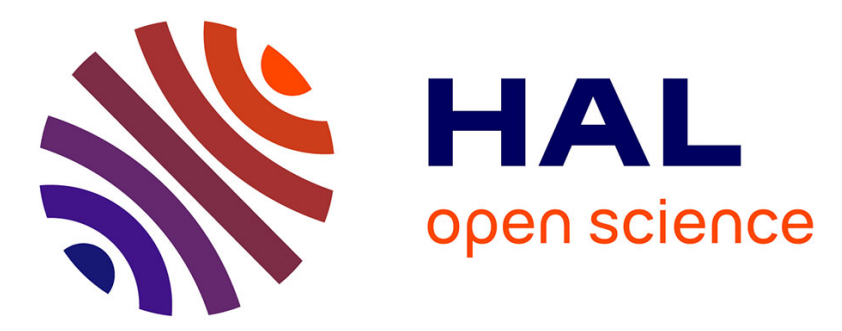

\title{
Influence of incentive networks on landscape changes: A simple agent-based simulation approach
}

Sébastien Caillault, François Miahle, Clémence Vannier, Sylvestre Delmotte, Conchita Kedowide, Fredéric Amblard, Michel Etienne, Nicolas Becu, Pierre Gautreau, Thomas Houet

\section{To cite this version:}

Sébastien Caillault, François Miahle, Clémence Vannier, Sylvestre Delmotte, Conchita Kedowide, et al.. Influence of incentive networks on landscape changes: A simple agent-based simulation approach. Environmental Modelling and Software, 2013, 45, p. 64-73. 10.1016/j.envsoft.2012.11.003 . hal01125774

\section{HAL Id: hal-01125774 \\ https://hal.science/hal-01125774}

Submitted on 6 Mar 2015

HAL is a multi-disciplinary open access archive for the deposit and dissemination of scientific research documents, whether they are published or not. The documents may come from teaching and research institutions in France or abroad, or from public or private research centers.
L'archive ouverte pluridisciplinaire HAL, est destinée au dépôt et à la diffusion de documents scientifiques de niveau recherche, publiés ou non, émanant des établissements d'enseignement et de recherche français ou étrangers, des laboratoires publics ou privés. 


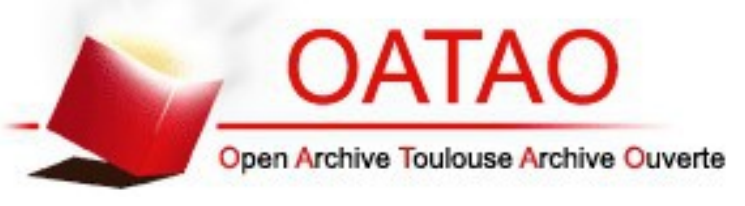

\section{Open Archive TOULOUSE Archive Ouverte (OATAO)}

OATAO is an open access repository that collects the work of Toulouse researchers and makes it freely available over the web where possible.

This is an author-deposited version published in : http://oatao.univ-toulouse.fr/ Eprints ID : 12348

To link to this article : DOI :10.1016/j.envsoft.2012.11.003

URL : http://dx.doi.org/10.1016/j.envsoft.2012.11.003

To cite this version : Caillault, Sébastien and Miahle, François and Vannier, Clémence and Delmotte, Sylvestre and Kedowide, Conchita and Amblard, Fredéric and Etienne, Michel and Becu, Nicolas and Gautreau, Pierre and Houet, Thomas Influence of incentive networks on landscape changes: A simple agent-based simulation approach. (2013) Environmental Modelling and Software, vol. 45. pp. 64-73. ISSN $1364-8152$

Any correspondance concerning this service should be sent to the repository administrator: staff-oatao@,listes-diff.inp-toulouse.fr 


\title{
Influence of incentive networks on landscape changes: A simple agent-based simulation approach ${ }^{\text {th }}$
}

\author{
S. Caillault ${ }^{\mathrm{a}}$, F. Mialhe $^{\mathrm{b}}$, C. Vannier $^{\mathrm{c}}$, S. Delmotte ${ }^{\mathrm{d}}$, C. Kêdowidé $^{\mathrm{e}}$, F. Amblard ${ }^{\mathrm{f}}$, \\ M. Etienne ${ }^{\mathrm{g}}$, N. Bécu ${ }^{\text {h}}$, P. Gautreau ${ }^{\mathrm{b}}$, T. Houet ${ }^{\mathrm{i}, *}$ \\ a GEOPHEN UMR 6554 LETG, Université de Caen Basse-Normandie, BP8156, 14032 Caen Cedex, France \\ b PRODIG UMR 8586 CNRS, Université Panthéon-Sorbonne/Denis Diderot, 5 rue Thomas Mann, 75013 Paris, France

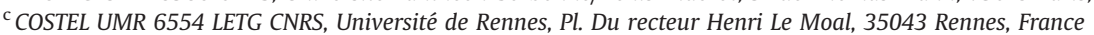 \\ d INRA UMR Innovation, 2 Place Pierre Viala, 34070 Montpellier Cedex, France \\ e ENeC UMR 8185 CNRS, Universités Paris 8, 2 rue de la Liberté, 93526 Saint-Denis, France \\ f IRIT-UT1, Université de Toulouse 1, 2 rue doyen Gabriel Marty, 31042 Toulouse Cedex 9, France \\ I INRA Avignon, Unité Ecodéveloppement, Site Agroparc, 84914 Avignon Cedex 9, France \\ h PRODIG UMR 8586 CNRS, Université Panthéon-Sorbonne, 2 rue Valette, 75005 Paris, France \\ ${ }^{\mathrm{i}}$ GEODE UMR 5602 CNRS, Université de Toulouse, 5 allée Antonio Machado, 31058 Toulouse Cedex, France
}

\begin{abstract}
A B S T R A C T
The aim of this paper is to implement a simple model for exploring the influence of different multi-scale incentive networks affecting farmer decision on landscape changes. Three scales of networks are considered: a global 'policy' network promoting specific land uses, an intermediate 'social' network where land use practices are shared and promoted collectively and a local 'neighborhood' network where land use practices are influenced by those of their neighbors. We assess the respective and combined influence of these networks on landscape pattern (fragmentation and heterogeneity) and dynamics, taking into account agronomic constraints (assimilated to crop successions). Simulations show that combination of incentive networks does not have linear and/or cumulative influence on landscape changes. Comparison of simulated scenarios highlights that a combination of two networks tends to improve landscape heterogeneity and fragmentation; scenarios combining all networks could lead to two opposite landscape configuration illustrating emergence of landscape dynamics. Finally, this study emphasizes that landscape complexity has also to be understood through the multiplicity of pathways of landscape changes rather than the assessment of the resulting landscape patterns.
\end{abstract}

\section{Introduction}

Land use/cover change (LUCC) is the result of the interaction between humans and their environment. The impact of agriculture is unparalleled to other LUCC in its combination of spatial extent and intensity of influence (Lambin et al., 2001). Agricultural development has induced dramatic consequences on habitats, water quality, and biodiversity (Butler et al., 2007; Gordon et al., 2008) by modifying landscape patterns (i.e. composition and structure) and hydro-chemical processes (nutrient cycles, etc.). LUCC comes from the actions and interactions of different stakeholders operating at different levels who are continuously influencing the structure and composition of the landscape (Valbuena

\footnotetext{
Thematic Issue on Spatial Agent-Based Models for Socio-Ecological Systems.

* Corresponding author. Tel.: +33 (0)5 615036 28; fax: +33 (0)5 61504275

E-mail address: thomas.houet@univ-tlse2.fr (T. Houet).
}

et al., 2010). Agricultural landscape patterns are driven by multiscale forces - from the global economy, international policies, and soil properties at regional, farm and field scale, to local social choices and individual practices (Veldkamp et al., 2001). An increasing number of agricultural products are now embedded in global commodity chains, i.e. "a network, or rather a set of networks, and processes that result in an end-product or commodity and linking labor, production, households, states, and enterprises to one another within the global economy" (Gereffi and Korzeniewicz, 1994). Such a global network provokes production and practice changes in response to social, environmental and economic demands from different stakeholders at different scales. In contrast, local factors, such as the "neighborhood," are still influential and explain the diffusion by contagion of farming innovations (Daudé, 2004). Intermediate scale factors - regional or national - such as union membership, may also influence the decisions of farmers concerning their land uses. Farming decisions 
result from the internal representations and beliefs of farmers that may evolve with information given and diffused by other farmers, institutions, associations and other networks (Wauters et al., 2010). Thus, most LUCC in rural regions occurs at the farm scale where these driving forces are integrated (Kristensen et al., 2001; Baudry and Thenail, 2004).

Landscape change models are particularly appropriate for testing and assessing the influence of social, economic and ecological processes, their dynamics, and interactions that modify landscape patterns (Baker, 1989; Gaucherel and Houet, 2009; Zimmerman, 2008). A common approach to simulating LUCC as a consequence of collective or individual decisions and actions is through the use of agent-based models (ABM) (Matthews et al., 2007; Parker et al., 2003, 2008; Robinson et al., 2007; Treuil et al., 2008). ABMs are particularly well suited to modeling different types of networks that can lead to the emergence of new spatial patterns (Bretagnolle et al., 2000; Gimblett, 2001; Urbani, 2006). ABMs help to assess the influence of land use policies, the interactions between land uses (Rouan et al., 2012), on socioecological systems based on different scenarios (Le et al., 2010; Parry et al., 2012; Robinson et al., 2012) but also to identify possible land use strategies based on the companion modelling framework (Etienne, 2006; Simon and Etienne, 2010). Because the driving forces of LUCC in agricultural landscapes are numerous and act at multiple scales (Bürgi et al., 2004), the assessment of their respective and combined influence still remains a challenge. Although landscapes exhibit a hierarchical structure (Burel and Baudry, 2003), the modeling of involved multi-scale processes has not always lead to the simulation of realistic landscapes. Thus, land use systems are characterized by complex interactions between human decision-making and their biophysical environment (Smajgl et al., 2011). LUCC ABMs are particularly well suited for representing complex spatial interactions under heterogeneous conditions and for modeling decentralized, autonomous decisionmaking (Parker et al., 2003). Furthermore, the use of neutral landscape models (Gardner et al., 1987; O'Neill et al., 1992), which are simple models applied on theoretical landscapes, has been recognized as a potential technique for better understanding of landscape dynamics (Gaucherel et al., 2006). These models help to include and study the interactions between multiple driving forces and thus are able to tackle the complexity of the processes involved (McAllister et al., 2005; Houet et al., 2010b), as the use of ABMs on neutral landscapes shows promising results (Brown et al., 2004).

The aim of this paper is to implement a theoretical - neutral model for exploring the influence of different multi-scale incentive networks, both individually and in various combinations, on landscape pattern and dynamics. An incentive network is defined as a social network, composed by individuals and/or institutions among which information is diffused to favor a certain action/ decision to promote a land use type. In our model, three scaled networks influence farmers' decisions: a global 'policy' network promoting specific land uses through incentives to farmers, an intermediate 'social' network where land use practices are shared and promoted collectively, and a local 'neighborhood' network where the land use practices are influenced by those of their neighbors. This multi-layered network approach is quite original in the field of LUCC/landscape modelling and shows some similarities to studies modelling some social relations in the landscape (Berger, 2001; IMAGES, 2004).

\section{Methodology: model description and experiments}

The NetLogo platform (version 4.1 - Wilensky, 1999) has been used to develop the IRIUS model (Impact des Réseaux d'Influence sur l'Utilisation du Sol i.e. Impact of incentive networks on land use). Its description follows the ODD protocol (Grimm et al., 2006, 2010).

\subsection{Overview}

2.1.1. Purpose

The purpose of this model is to explore and assess the impact of different and multi-scale incentive networks that operate at three scales (global, social and neighborhood) on farmers' land use decision-making and consequently on landscape pattern.

\subsubsection{Entities}

The model includes various entities:

'farmers' (agents/individuals). Agents have limited cognitive capacities. They have to respect agronomic constraints (crop succession). After receiving incentives of land use types from networks, they prioritize them according to the agronomic constraints related to crops succession and choose the highest recommended one. In case of contradictory incentives, they can choose a convenient land use type randomly.

'farm' (spatial units). Each farm belongs to a farmer. The overall landscape is composed of all spatial units. Each spatial unit has two state variables: land use type and age. The land use type is approached under a simplified representation with a numerical code (1,2 or 3 ) that is initially randomly assigned to each spatial entity. Land use types change over time according to farmer decisions and agronomic constraints. Such constraints define the maximum duration of each land use type ('age') accordingly to Castellazzi et al. (2008, 2010) and Houet et al. (2010a). When the maximum value of the age is reached, the current land use type must change to one of the two other possible land use types.

'global network' (environment). This entity simulates a public policy encouraging farmers to adopt specific land use practices according to a global land use assessment made at the landscape scale. The network is composed of all farmers, who all receive the same incentive from this global - public policy - entity.

'social network' (collective). This entity simulates voluntary membership in formal or informal associations (e.g. farmers' unions, lobbies, etc.) that influence farmers' practices. All farmers belong to one of the five user-defined social groups, each encompassing equal proportions of farmers.

'local network' (collective). This entity intends to simulate the influence of neighbors' land use practices. Indeed, some authors have shown that some local land use changes could occur for various - environmental or economic reasons (Daudé, 2004). The diffusion of such land uses changes is theoretically explained by the imitation and adoption by one farmer of the most common practice that occurs in the neighboring farms (Gotts and Polhill, 2009; Kaufmann et al., 2009), even if this effect is sometimes hard to detect in reality (Schmit and Rounsevell, 2006). As such, each farmer tends to adopt the dominant land use within his neighborhood, represented in the network by the eight adjacent farms (Moore neighborhood).

\subsubsection{Spatial and temporal scales}

The model is run for 250 time steps, where one time step corresponds to one cropping season (which could represent as much as one year or as few as several months). The landscape is composed of $25 \times 25$ spatial units, or 625 farms. To avoid border effects, the local network is defined by the Moore neighborhood of each cell within a torus space (Kimura, 2002).

\subsubsection{Process overview and scheduling}

At each time step, each farmer receives an incentive from each network that encourages him to produce or adopt a specific land use type. According to the age of the current land use, each farmer lists the possible land use types that he is able to implement. A set of decision rules is used to simulate the decision-making of farmers to choose a land use type for the next time step based on the received incentives. The landscape is updated with new land uses implemented within each cell.

\subsection{Design concepts}

\subsubsection{Basic principles}

The interest of this study lies in the simple model which allows for testing of all possible combinations of networks and assessing their influence on landscape pattern and dynamics.

\subsubsection{Emergence}

Emergence may occur by specific combinations of initial situations and network incentives. The local network tends to homogenize practices locally. The global network favors less frequent land use types by giving feedback on previous land uses. The social network influences the practices of groups of farmers. The generated landscape configuration is not predictable and strongly depends on the initial randomized distribution of social networks and on initial randomized landscape configuration. According to the initial conditions and the number and type of active networks during the simulation, landscape patterns could emerge from individualbased decisions. 


\subsubsection{Adaptation}

Farmers do not have a wide range of possible decisions. They adopt the land use type suggested by the majority of the networks if it is consistent with the agronomic constraints. If not, the remaining recommended land use type is adopted. No individual initiative in the choice of land use type is simulated.

\subsubsection{Objectives}

Networks incite farmers to adopt the land use type that are recommended to them. 'Local' and 'social' networks encourage farmers to adopt the land use type used by the majority of their respective members (e.g. to maximize agricultura production). The 'global' network analysis in which the land use types are less represented at the landscape scale incites all farmers to adopt it (e.g. to improve landscape heterogeneity at an aggregated level to favor biodiversity preservation) (Poiani et al., 2000; Lindenmayer et al., 2006).

\subsubsection{Learning}

Neither farmers nor networks change their behavior according to their experience.

\subsubsection{Prediction}

No prediction activity is realized by any kind of agent or entity in the model.

\subsubsection{Sensing}

Farmers directly receive recommendations from 'social' and 'global' networks for a specific land use type. They themselves calculate the major land use type in their neighborhood, and use the result as a recommendation from the 'local' network to adopt this land use.

\subsubsection{Interaction}

Farmers react to incentives given by the 'global' and 'social' networks while they have direct (neighboring) interactions within their local network.

\subsubsection{Stochasticity}

We assume that landscape configuration at the initial step does not strongly affect landscape dynamics. As randomness occurs at the initialization, the modele can only specify land use ratios. The land use attribute and age of each cell are randomly allocated. The farmers' membership to a social group is also randomly chosen. Randomness also occurs while running the model: a 'blank' land use recommendation may be sent (e.g no land use type is favored). In such case, farmers would randomly choose a land use type among the possible land use type list. This case occurs for example when the three networks send the same incentives, i.e. suggest the same land use type (e.g. $2-2-2$ ) to a farm that has already reached its maximum land use age under that proposed configuration.

\subsubsection{Observation}

Assessing the influence of networks on landscape dynamics (Gustafson, 1998) is carried out using two quantitative indices: the Shannon Diversity Index (SDI) and the Patch Density Index (PDI). This is a standard way of analyzing landscape structure in landscape ecology (O'Neill et al., 1988; Burel and Baudry, 2003). The SD is described by Formula (1) and gives a synthetic value of landscape heterogeneity. The PDI describing landscape fragmentation simply equals the number of landscape patches for each land use type. A landscape patch is composed by identical contiguous landscape units (i.e. land use type).

$\mathrm{SDI}=\sum_{i=1}^{S}\left(p_{i} \cdot \ln \left(p_{i}\right)\right)$

$p_{i}$ - the number of spatial units (farms) of land-use type " $i$ " over the total number of spatial units

$S$ - total number of land-use types

Landscape pattern is considered here from the point of view of the combined evolution of landscape fragmentation and heterogeneity. A mean value of landscape heterogeneity and fragmentation is computed from the simulations made for each scenario. To assess and characterize the influence of each/combined network(s) on landscape pattern (heterogeneity and fragmentation), we used standard scores of these landscape indices. To exclude cases where class frequency is " 0 " ( $\operatorname{Ln} 0$ is impossible) we add 0.0001 for all classes in the formula, what explains why SDI is sometimes superior to 1 . These values of landscape heterogeneity and fragmentation make all scenarios comparable.

\subsection{Details}

\subsubsection{Initialization}

All simulations were run with an equal ratio of land use types. The number of social groups is user-defined, but was fixed to five in this study. Farmers are randomly assigned to one of the social groups which finally show equal numbers of farmers (125 here). The maximum 'age' for each land use can be selected from two possible values ( 5 or 10 ). The age of each land use (between 1 and the selected maximum age value) is randomly assigned for each cell. Finally, a user can activate (or not) the influence of one or several networks.

\subsubsection{Input data}

The model does not use external data sources.

\subsubsection{Submodels}

Creation, diffusion and processing (decision) of information are the main operators of the existing submodels. At every time step, farmers receive incentives from the networks in a single list, called a 'recommendation list'. Then, a new list of information is created according to current land use age, called a 'list of possibilities'. Fig. 1 summarizes submodels implementation.

The global network favors the minor land use at the landscape scale to maximize landscape diversity according to Deke (2008). Land use proportions are calculated for each time step. If two minor land uses are equal, the global network does not recommend any land use.

The local network reproduces a common farmer behavior that consists of imitating the most frequent agricultural practices in his neighborhood (Deffuant et al., 2002; Kaufmann et al., 2009). For each farmer, land use ratios are computed for the eight adjacent farms and the most frequent land use is recommended. In the case that two land uses occur equally in the neighborhood, the local network does not recommend any land uses.

The social network is promoting a common land use practice that is the most frequent within the social group each farm belongs to. It somehow replicates the impact of innovative land use practices diffusion (Saltiel et al., 1994). If two land use types are dominant, the social network does not recommend any land use type.

- The farmer's decision rule performs as follows: if the "recommendation list" contains a dominant land use type, and if this type is in the "list of possibilities" the farmer chooses it. If the "recommendation list" does not provide any land use recommendation (all null), the farmer randomly chooses a land use type from the list of possibilities. If the "recommendation list" does not contain a dominant land use type, it is randomly chosen from land use types listed in the list of possibilities (Fig. 1).

\section{Experiments}

Three kinds of experiments can be distinguished. First, type behaviors (in terms of landscape heterogeneity) are identified and characterized from the simulations. Then, some runs were made to assess model sensitivity to initial landscape configuration. Finally, some others, called scenarios, for evaluating the respective and combined influence of networks on landscape pattern and dynamics.

In a first step the observed behaviors from the outputs of the simulations were qualified. The term 'behavior' is used to characterize an evolution of the SDI in term of magnitude, variability and trend. Secondly, to assess model sensitivity to initial landscape configuration we designed an experiment to estimate the influence of initial land use and age patterns on results. The experiment crossed two archetypal initial configurations of land use spatial distribution (a scattered distribution versus a perfectly aggregated one $^{1}$ ) and two configurations for the initial age distribution (a random one versus age of all spatial units set to one). The influence of the initial spatial distribution for the social groups is not assessed as it does not evolve during the simulation and can thus be considered as a static variable. We therefore use the same random spatial distribution of the social groups for all the initial configurations tested. Each initial configuration is simulated 100 times. Thirdly, the respective and combined influence of networks on landscape pattern is assessed through the simulation of eight scenarios. Table 1 presents all scenarios and illustrates all possible combinations of networks. Each scenario is simulated 40 times, i.e. with 40 different initial configurations, to assess landscape changes variability. Scenarios are analyzed in the light of these behaviors to

\footnotetext{
${ }^{1}$ For the scattered distribution, the landscape is generated randomly, yet respecting equal distribution of each land-use. For the aggregated one, the landscape is split into three equal stripes, one for each land-use.
} 


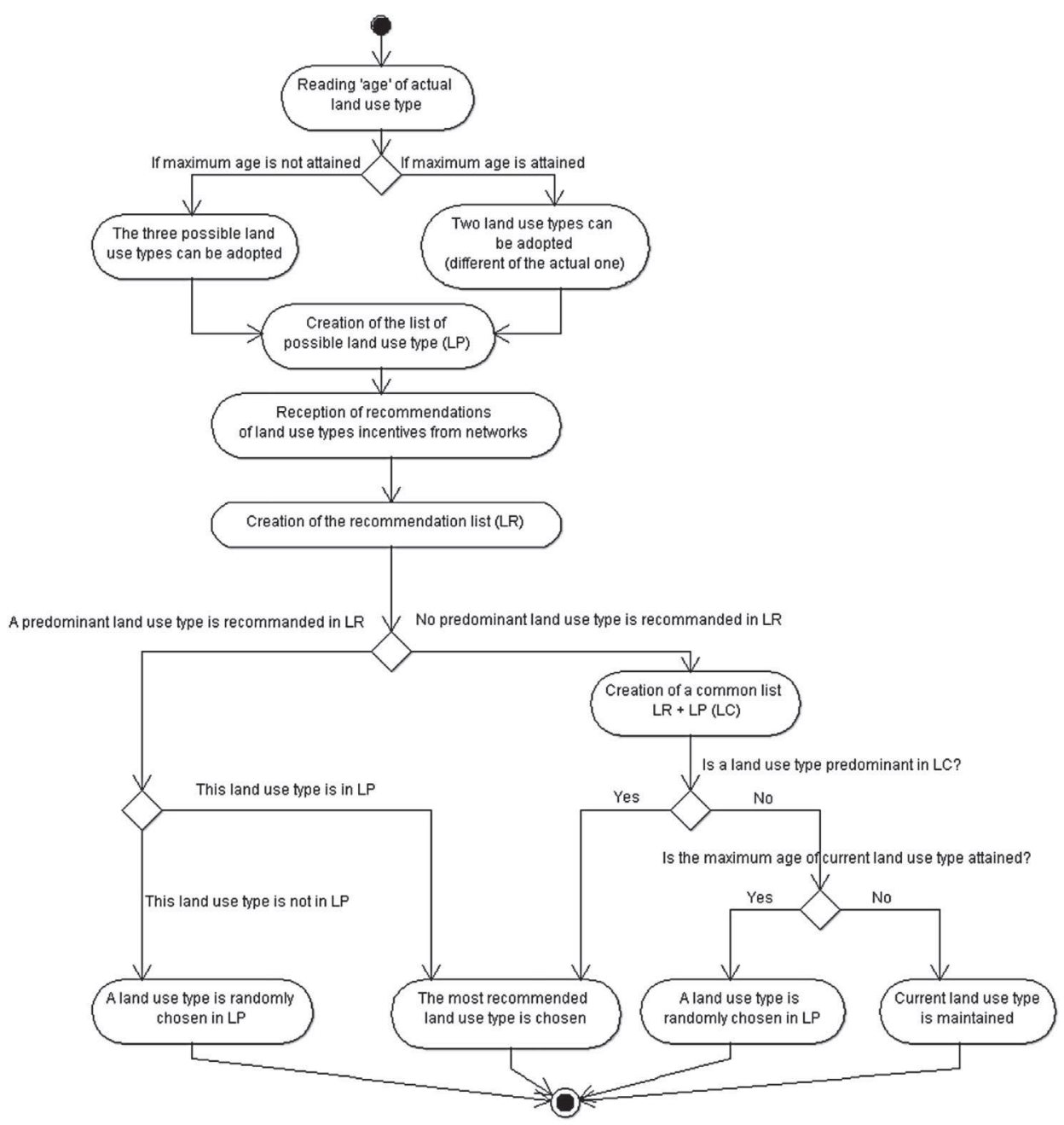

Fig. 1. Activity diagram summarizing land use type decision rules made by each farmer.

answer the following question: Does a scenario lead to a specific landscape heterogeneity behavior? We therefore study the influence of networks on landscape pattern (i.e. from the point of view of the combined evolution of landscape fragmentation and heterogeneity).

As detailed in paragraphs 2.1.3, 2.3.1 and 2.3.3, all other parameters are kept constant along the experimental design. The environment is a regular torus of $25^{*} 25$ ( 625 farms). The three land use types are equally represented and randomly allocated at the initialization. The number of social groups is kept constant to 5 . Initial landscape and social network configurations remain the same for all scenarios.

\section{Table 1}

Summary of the simulated scenarios.

\begin{tabular}{llll}
\hline \multirow{2}{*}{ Scenario } & \multicolumn{2}{l}{ Networks $($ Activated $=\mathrm{x} /$ Inactivated $=-$ ) } \\
\cline { 2 - 4 } & Local & Social & Global \\
\hline 1 & - & - & - \\
2 & $\mathrm{x}$ & - & - \\
3 & - & - & $\mathrm{x}$ \\
4 & - & $\mathrm{x}$ & - \\
5 & $\mathrm{x}$ & - & $\mathrm{x}$ \\
6 & $\mathrm{x}$ & $\mathrm{x}$ & - \\
7 & - & $\mathrm{x}$ & $\mathrm{x}$ \\
8 & $\mathrm{x}$ & $\mathrm{x}$ & $\mathrm{x}$ \\
\hline
\end{tabular}

\section{Results}

\subsection{Behaviors of landscape heterogeneity from simulations}

All simulations allow the identification of six main types of 'behaviors' of landscape heterogeneity. A first behavior of landscape heterogeneity (behavior A) shows high values (SDI $=1 \pm 0.1$ ) over time with small variations (Fig. 2b). At least two land use types tend to be aggregated into few landscape patches (Fig. 2a). Behavior Abis derivates from the first one: SDI trend is similar and only the mean value is a bit lower (0.8). Behavior B shows quite high SDI values $(\mathrm{SDI}=0.8)$ over the time with intermediate variations $( \pm 0.4)$ (Fig. 2b). One land use type is dominant over the landscape with scattered patches of the two others land use types. SDI variations are explained by the shift from a dominant land use type to another (Fig. 2a). Behavior B-bis derivates from the previous one: it is similar with a lower mean SDI value (0.6) (Fig. 2b). Behavior C is characterized by stable phases of SDI high values, punctuated by abrupt changes leading to shorter phases of low SDI values (Fig. 2b). The first phase in the experiments illustrates a heterogeneous landscape with scattered land use types. The second phase in the experiments illustrates a landscape dominated by one land use type (Fig. 2a). Behavior D is characterized by a first phase similar to behaviors A or A-bis, but shows then a decrease of SDI that tends to 0.5 with variations from \pm 0.1 to \pm 0.4 (Fig. 2b). Landscape is dominated by one land use type and the two others are scattered 

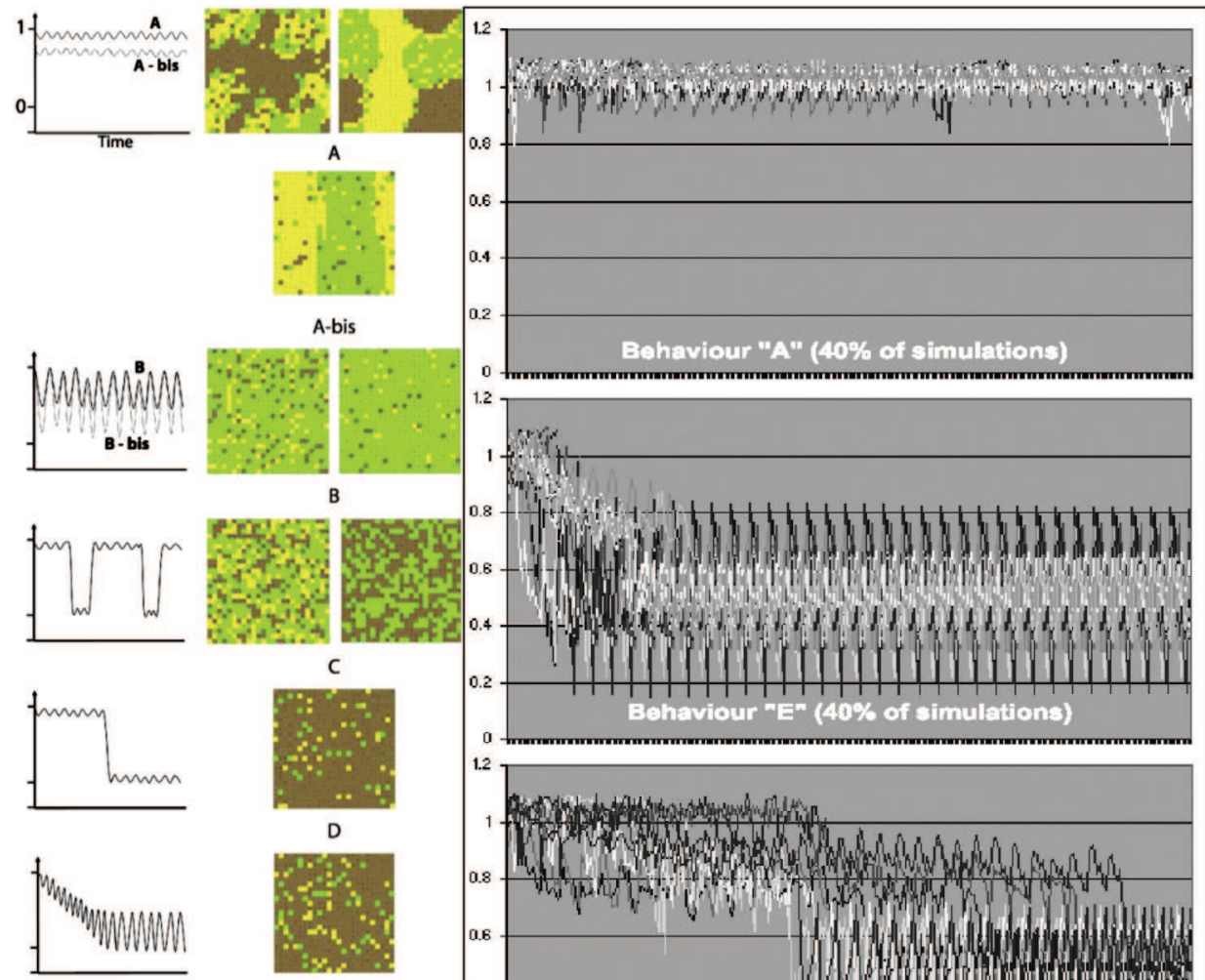

E
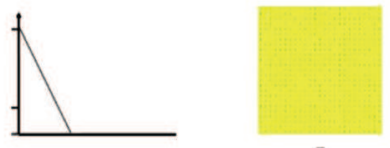

$\mathrm{F}$

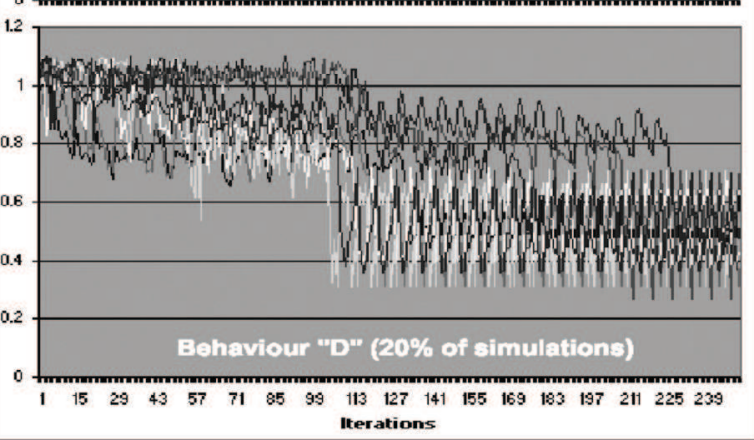

a

b

Fig. 2. Examples of landscape heterogeneity behaviors: (a) summary of all synthesized types of behaviors, (b) Illustration of the three behaviors inherited from scenario 8 (SDI variations [Y-axis] over 250 time steps [X-axis]).

(Fig. 2a). Behavior E could be distinguished from the behavior D by a quick decrease of SDI from 1 down to 0.5 associated with an increase of the variations from \pm 0.2 up to \pm 0.6 (Fig. 2b). Final landscape is dominated by one land use type with a higher proportion of the two others scattered land use types (Fig. 2b) compared to behavior D. Behavior F shows a SDI value that fastly decreases to 0 and remains stable over time, i.e. landscape remains homogenous, dominated by one land use type. All of these behaviors are summarized in Table 2 and Fig. 2.

\subsection{Influence of initial landscape configuration on observed behaviors}

Fig. 3 shows the proportion of resulted behaviors when all networks - i.e. local, global and social networks - are activated (this is the more general and realistic case) for five different initial landscape configuration settings. The influence of different initial scattered landscapes is assessed through two different randomly generated initial landscapes (Fig. 3a and b). Differences range from

Table 2

Summary of landscape heterogeneity behaviors observed for all simulations.

\begin{tabular}{|c|c|c|c|c|}
\hline Behavior & Description & $\begin{array}{l}\text { Initial SDI } \\
\text { value }\end{array}$ & $\begin{array}{l}\text { Final SDI } \\
\text { value }\end{array}$ & $\begin{array}{l}\text { Oscillations } \\
\text { amplitude }\end{array}$ \\
\hline A & $\begin{array}{l}\text { Simulations show low amplitudes of the SDI value. Landscape heterogeneity } \\
\text { remains high over the time. }\end{array}$ & 1 & 1 & 0.1 \\
\hline A-bis & A-bis behavior is similar to A but with a slightly lower SDI value. & & 0.8 & 0.1 \\
\hline B & $\begin{array}{l}\text { Simulations show intermediate amplitudes of the SDI value. Landscape } \\
\text { heterogeneity remains quite high over the time. }\end{array}$ & & 0.8 & 0.4 \\
\hline B-bis & B-bis behavior is similar to A but with a slightly lower SDI value. & & 0.6 & 0.4 \\
\hline $\mathrm{C}$ & $\begin{array}{l}\text { Simulations show low amplitudes of the SDI value but with iterative strong } \\
\text { decreasing of SDI value for } 10-20 \text { time steps. }\end{array}$ & & 1 & $0.1-0.8$ \\
\hline $\mathrm{D}$ & $\begin{array}{l}\text { Simulations start with high SDI values ( } 1) \text { and then slowly converge to low } \\
\text { value }(0.5) \text {. Oscillations remain low at the beginning and the amplitude is } \\
\text { around } 0.4 \text { at the end. }\end{array}$ & & 0.5 & 0.1 to 0.4 \\
\hline E & $\begin{array}{l}\text { Simulations show a quick decreasing of SDI value from } 1 \text { down to } 0.5 \text {. } \\
\text { Oscillations are low at first and then increase until an amplitude of } 0.6 \text {. }\end{array}$ & & 0.5 & $0.2-0.6$ \\
\hline $\mathrm{F}$ & $\begin{array}{l}\text { SDI value strongly decreases to } 0 \text { and then remains stable. Landscape is } \\
\text { homogenous over time. }\end{array}$ & & 0 & 0 \\
\hline
\end{tabular}




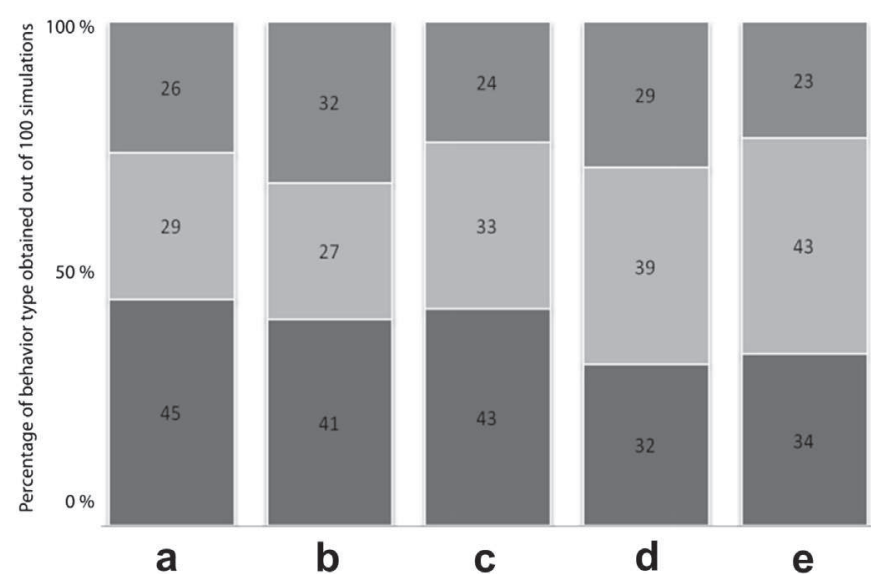

Fig. 3. Proportions of behaviors (behavior A - dark gray; behavior D - intermediate gray; behavior E - dark gray) for different initial configurations under scenario 8: (a) scattered land uses and random age version 1, (b) scattered land uses and random age version 2, (c) scattered land uses and all ages set to 1, (d) aggregated land uses and random age, (e) aggregated land uses and all ages set to 1 .

2 to $6 \%$. A similar range is found when comparing configurations with all land uses' age set to one (Fig. 3c) with initial configurations defined by randomized land use ages (Fig. 3a and b). This indicates that the initial distribution of ages has no influence on the final simulation outputs. Indeed, after 10 to 15 time steps, configurations with different initial age patterns can no longer be differentiated.

On the contrary, simulations made with scattered and aggregated initial land uses do show some differences. An aggregated initial landscape leads to a homogeneous final landscape in approximately $77 \pm 1 \%$ of the cases (behaviors D + E in Fig. $3 \mathrm{~d}$ and e) while the same final state is observed with a scattered initial landscape in approximately $67 \pm 2 \%$ of the cases (behaviors $D+E$ in Fig. $3 a-c)$. Hence, the initial landscape heterogeneity has a slight influence on the final result (a weight of approximately $\pm 10 \%$ if we consider the mean Shannon index), but the final simulation outputs are mainly influenced by the three networks and their interactions during the course of the simulation.

\subsection{Influence of networks combination on behaviors of landscape heterogeneity}

In order to evaluate the impact of the activated networks on the landscape heterogeneity, the proportions of the behavior for each scenario are estimated from the sensitivity analysis (Table 3 ).

On one hand, four scenarios (scenarios 1, 3, 4 and 5) show stable behaviors. When no network is taken into account (Scenario 1), the landscape always remains clustered with high heterogeneity values

Table 3

Proportion of behaviors for each scenario.

\begin{tabular}{llllllllll}
\hline Scenario & $\begin{array}{l}\text { 'Age' } \\
\text { value }\end{array}$ & A & A-bis & B & B-bis & C & D & E & F \\
\hline 1 & $5 / 10$ & $100 \%$ & & & & & & & \\
2 & 5 & & $15 \%$ & & & & & $85 \%$ & \\
& 10 & & $18 \%$ & & & & & $82 \%$ & \\
3 & $5 / 10$ & & & & & & & & $100 \%$ \\
4 & $5 / 10$ & & & & & $100 \%$ & & & \\
5 & $5 / 10$ & $100 \%$ & & & & & & & \\
6 & 5 & $38 \%$ & $5 \%$ & & $57 \%$ & & & & \\
& 10 & $37 \%$ & $13 \%$ & & $50 \%$ & & & & \\
7 & 5 & & & $100 \%$ & & & & & \\
& 10 & & & $78 \%$ & $23 \%$ & & & & \\
8 & 5 & $42 \%$ & & & & & $19 \%$ & $39 \%$ & \\
& 10 & $75 \%$ & & & & & & $25 \%$ & \\
\hline
\end{tabular}

following behavior A (Fig. 2). The scenario simulating the influence of the 'global network' (scenario 3 ) always results in a homogeneous landscape (behavior F). The scenario integrating the influence of the 'social network' (scenario 4) produces a landscape exhibiting high heterogeneity with iterative phases of homogeneity (behavior C). Combining local and global networks (scenario 5) always exhibits a clustered landscape (behavior A).

On the other hand, four other scenarios produced contrasting results. Each of these scenarios (scenarios 2, 6, 7 and 8) provides contrasting behaviors. Social network (scenario 2) can provide either a clustered landscape with high heterogeneity values (behavior A-bis in $15 \%$ of the simulations), or a less heterogeneous landscape (behavior $\mathrm{E}$ in $85 \%$ of the simulations) (see Table 3 ). Combining global and social (scenario 7) networks exhibits a heterogeneous landscape (behavior B/B-bis) most of the time (78$100 \%$ ). Combination of local and social networks (scenario 6) leads to more complex results. Landscape heterogeneity varies from 0.6 ( $50 \%-58 \%$ of behavior B-bis), 0.8 (5-13\% of behavior A-bis) to 1 (38\% of behavior A). Thus, combining two undifferentiated networks always improves landscape heterogeneity over the time.

When all networks are influencing farmers' decisions (scenario 8 ), two opposite types of landscape patterns emerge from differentiated behaviors. Simulated landscapes can be either clustered ( $42 \%$ of behavior A) or quite homogeneous (39\% of behavior E, 19\% of behaviors D). Networks might imply effects leading to diverging landscape heterogeneity.

\subsection{Influence of networks on landscape pattern}

Landscape pattern is considered here from the point of view of the combined evolution of landscape fragmentation and heterogeneity. Fig. 4 presents the distribution of the different synthesized indices for each scenario.

Concerning the influence of the user-defined 'age' threshold values, Fig. 4 shows that this parameter does not strongly affect landscape pattern. Whatever the number of possible successive land use occurrences (the maximum age), the mean values of landscape heterogeneity (SDI) and fragmentation (PDI) are close or similar for each scenario. However, a greater age value seems to slightly reduce landscape fragmentation independently from scenarios (Fig. 4).

Scenario 1 (1_5/10 in Fig. 4) is characterized by random land use changes and without activated network exhibits the highest landscape heterogeneity and fragmentation. This may result from the random initial landscape configuration. Global network(Sc3, i.e. 3_5 and 3_10 in Fig. 4) produces the least heterogeneous and fragmented landscapes. The combination of global and local networks illustrates the interest in using both of these landscape indices. Indeed, if the fragmentation (PDI) remains within low values in both scenarios 2 and 5 , heterogeneity (SDI) dramatically increases in scenario 5 with an original landscape pattern (behavior A).

Fig. 5 illustrates the combined influence of networks. When comparing scenario 2 (local network only) and 6 (social and local networks), the data show that combining social and local networks increases both fragmentation and heterogeneity of landscape pattern. Combining global and local network positively affects heterogeneity. Finally, it appears that the social network tends to increase heterogeneity of the landscape. The global network has significant effect when it is combined with the local network only. The local network has an opposite effect on landscape pattern. Combined with the social network, it equally reduces fragmentation and heterogeneity. Combined with the global network, it dramatically increases landscape heterogeneity and slightly increases its fragmentation. Fig. 5 also stresses the impact of a higher age variable (i) on heterogeneity which is higher in case 

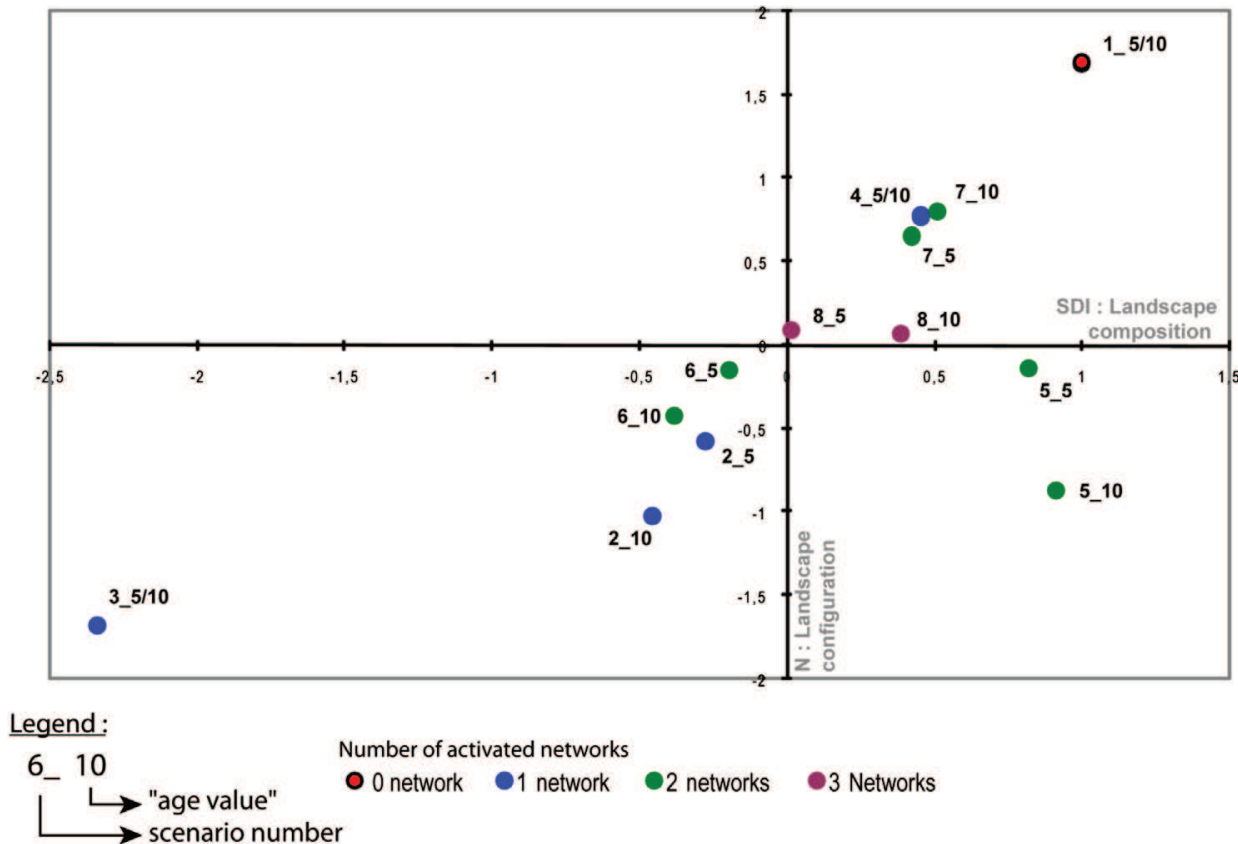

Fig. 4. Landscape heterogeneity and landscape fragmentation standard scores for each scenario with threshold values of 5 and 10 for the 'age' value, i.e. the maximum land use duration (e.g. scenario 2 with 5 and 10 threshold 'age' values is annotated 2_5 and 2_10).

of scenario 8 and lower in scenario 2 and 6 and (ii) on fragmentation which is lower in case of scenario 2, 5 and 6.

\section{Discussion}

\subsection{Understanding landscape pattern complexity}

This study illustrates how a landscape can reveal complex patterns under the influence of different multi-scale networks. In the case of a global network favoring a unique land use, a landscape is characterized by a great homogeneity. Landscape pattern resulting from the influence of the social network (behavior $\mathrm{C}$ ) depends on the spatial distribution of social groups (observed from visual interpretation). However, for a specific scenario and a given initial landscape configuration, different simulated landscape patterns can be obtained. The differing possible evolutions in landscape changes illustrate divergence in landscape dynamics. In the case of the single influence of the local network (scenario 2),

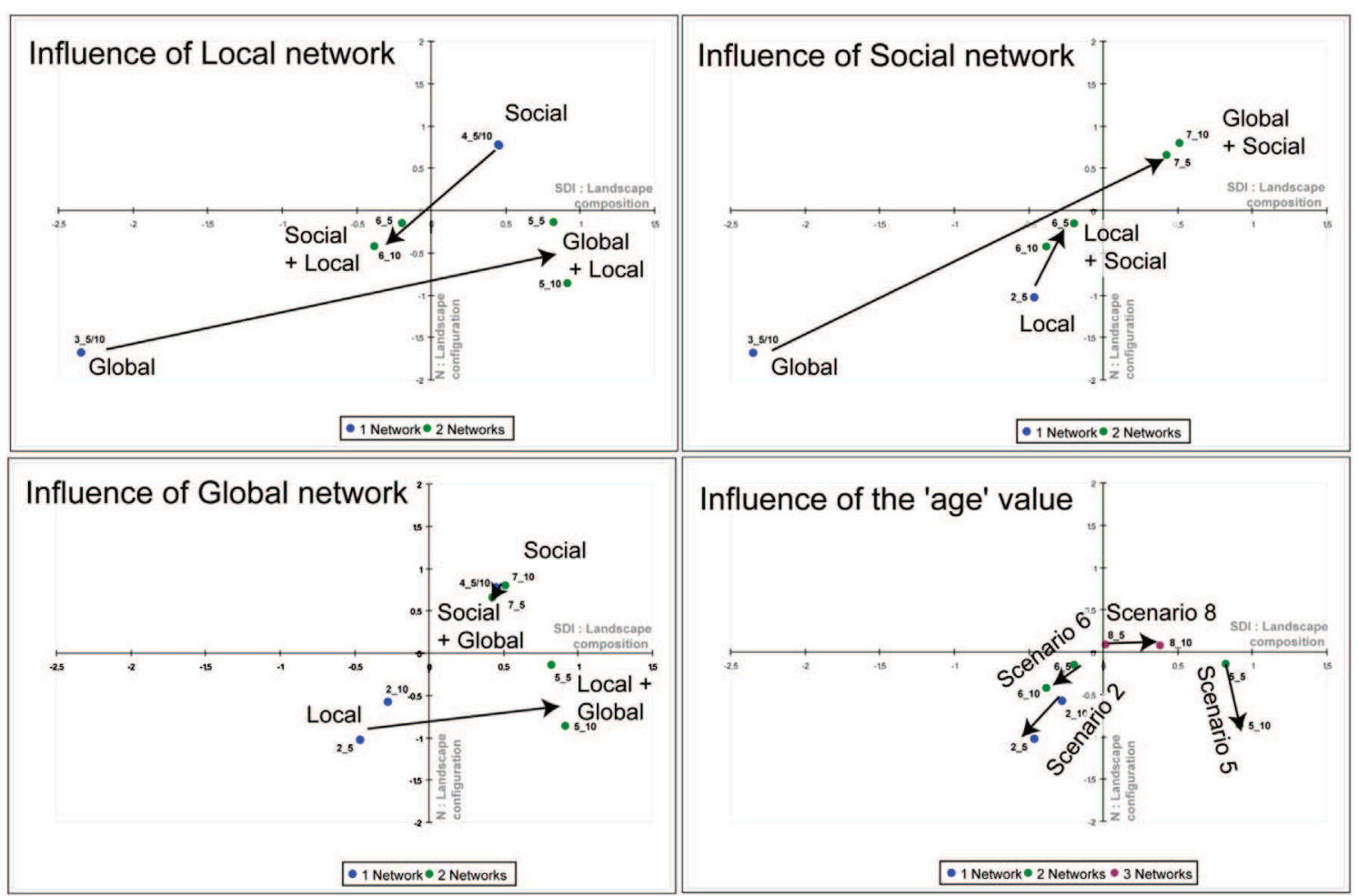

Fig. 5. Respective influence of the maximum duration of land use types and of local, social and global networks on landscape pattern. 
two behaviors can be distinguished (A-bis/E). Some "noise effect" illustrated through scattered distribution of land use types affecting landscape pattern can be observed and explained by the modeled agronomic constraints (defined as a land use age), as well as the initial landscape configuration. These results indicate, that local properties of a landscape strongly influence possible future landscape pattern and lead to different trajectories and potential impacts of LUCC. Based on simple rules and a theoretical landscape, these findings validate results found by Houet et al. (2010a) which are based on two different observed case studies. In other words, bifurcations of land use and land cover changes signify that emergence phenomena are occurring as new landscape dynamics.

Does a specific network favor emergence of landscape dynamics? Analysis of Table 3 shows that, when no networks are activated, the resulting - clustered - landscape pattern ( $100 \%$ of behavior $A$ ) is similar to results inherited from the Schelling model (Daudé and Langlois, 2006), but with three (land use) classes instead of two. On the other hand, diverging behaviors of landscape pattern appear for scenarios 2 (local network), 6 (local + social networks), 7 (social + global networks) and 8 (all networks). Thus, there is no specific network that leads to diverging landscape dynamics. However, the assumption could be raised that the more combined networks, the more emergence occurs, i.e. more alternative future landscape structures and dynamics. Indeed, two scenarios (of the 3) combining two networks and scenario 8 combining all networks, lead to at least two possible behaviors. But it appears in this case, that the combination of more networks (scenario 8) does not lead to more landscape heterogeneity. The complexity in the scenario is revealed by the multiplicity of pathways of landscape changes and not through the resulting spatial pattern of landscape.

This illustrates how difficult it is to understand and explain landscape pattern. It is even more obvious when multiple networks are considered. But this study has also given some key elements to better understand landscape pattern: (1) combination of incentive networks does not have simple cumulative influence on the direction and magnitude of landscape changes; (2) emergence phenomena occur and rely more on the temporal dimension of landscape pattern (bifurcation of landscape dynamics, multiple landscape trajectories) than on its spatial dimension (spatial design of land use and cover changes).

This paper also highlights that landscape changes rely to the path-dependence concept (North, 1990). When studying and understanding real landscape patterns, it is essential to look backward, i.e. to consider its dynamics and the concerned driving forces (Dearing et al., 2010). More generally, simulated landscape patterns inherit their present configuration from previous landscape configurations. If reality is obviously more complex, decisionmaking is passive and if we do not consider unpredictable changes, we can conclude that part of landscape dynamics is markovian. Such understanding of past changes is essential prior simulating futures landscape changes. This approach could be very useful for assessing alternative landscape futures from a theoretical perspective (Bolte et al., 2007; Houet et al., 2010a; Bryan et al., 2011).

\subsection{Model limitations and future improvements}

The main limitations of the model are threefold: the first concerns the simplistic hypotheses, while the remaining two relate to the study of the model behavior (i.e. the difficulty imposed by the stochasticity of the model as well as the lack of deepened study of the model behavior without the agronomic constraints). This being said, such limitations should be reduced according to the model aims and results. As a reminder, the model was built to tackle the simultaneous influence of multiples networks to which a farmer might belong and the agronomic constraints that farmers must take into account. In most models with agent-based social simulation dealing with environment, those two aspects are rarely combined. Either modelers include (mostly in abstract models on social influence) networks without including any constraint concerning the choice of the agent (the fact that the agent "farmer" has to change his/her practice regularly), or the models are very detailed concerning the level of the farm management but do not take into account any external social influence. In this model we combine both aspects. Even if the representation of each dynamic (social and environmental) is simplified, such a combined methodology is essential for understanding landscape dynamics.

The considered hypotheses are simplistic and could be refined in future work. On one hand, one of the limitations that we assumed was that each kind of network had the same influence on farmers' decisions. This is obviously not the case as different social networks have quite different weights in the decision-making process. An idea to be included that would enable to study such an evidence of the differentiated influence of the different network, while keeping a reasonable parsimonious approach, would be to weigh the different networks in the decision-making algorithm and to study different scenarios corresponding to different weighting. However, such simple assumptions have lead to some interesting results that were not easy to interpret.

On the other hand, an important potential option would be to justify and strengthen our findings with an empirical study set up using our model and realistic data. Taking for instance a realistic landscape at initialization, using agronomical constraints more intensively by choosing the exact constraints corresponding to different types of land uses or land covers on a given case study, and including real social networks coming from sociological interviews would indeed improve the interest of such a model for decisionmakers.

Concerning the study of the model's behavior, one of the weak points, in terms of classical sensitivity analysis techniques, concerns the randomness of the model. As described in this work, the model is based on randomized initialization of the landscape and randomized choice of land use when the farmer faces an equal influence of two networks. Both the use of realistic data to initialize the landscape and the weighing of social networks would enable to solve such problems.

Finally, the interest of the proposed agent-based model consists in its theoretical and parsimonious approach using neutral landscape modeling principles to study landscape dynamics paths. Parker et al. (2003) have identified this issue in their multi-agent systems/LUCC models typology focusing on the possible use of such models. Therefore, results show that the analysis of the dynamic path(s) of the system may be of relevance [...] and even more when spatial heterogeneity impacts path-dependent outcomes (Parker et al., 2003). This theoretical approach has permitted to illustrate that - real - landscape configuration as well as social structure inherently influence landscape changes and how simple environment-human interactions combined with policy and institutional changes may affect landscape paths.

Thus, this study contributes to the existing literature by illustrating the interest of combining approaches related to landscape ecology and LUCC modeling for at least two reasons: (1) it improves knowledge of socioeconomic-environmental linkages and the analysis of the response of a system to exogenous/endogenous influences (Parker et al., 2002); (2) it is complementary to other studies focusing on human-environment interactions in agricultural systems (Berger, 2001; Schreinemachers and Berger, 2011). For instance, to simulate the diffusion of water management innovation in Chile, Berger (2001) uses a network-threshold value approach as described by Valente (1995). In an attempt to fit to empirical observation of social network structures, two distinct 
communication networks were modeled, but no information spillover between the networks was introduced. In a recent paper, Schreinemachers and Berger (2011) present a Mathematical Programming based Multi Agent Systems approach (MP-MAS) which includes a technology diffusion module. The diffusion process is modeled as frequency-dependent contagion effect among neighboring agents. What we refer to as the global policy network in this paper, is represented in MP-MAS through the adoption of the first segment of agents (early adopters) but once the diffusion process is engaged, no interactions between networks of different scales are considered anymore.

We believe that this paper can contribute to the existing literature by exploring and suggesting novel ways to model diffusion processes in multi-agent simulation. Integrating the relations between the different levels of incentive networks as proposed here, is an attempt to better represent individual choices and adaptation processes in a society of communication where incentives and solicitations are permanent. This paper does not aim operational effectiveness but exploratory research by showing, through a theoretical case, what are the effects of juxtaposing incentive networks of different scales on diffusion processes.

\section{Conclusion}

The simulation approach developed in this paper is answering a few questions about the respective and combined influence of different kinds of networks on landscape pattern, taking into account agronomic constraints. Only the global 'policy' network favors landscape homogeneity (with various land use types for each time step), while the local 'neighborhood' network induces average landscape heterogeneity (SDI $=0.4)$ with a complex variability. The social network favors a higher heterogeneity $(\mathrm{SDI}=0.8)$, but strong variations of landscape heterogeneity for short intervals. Combination of two networks generally increases landscape heterogeneity. Behaviors of landscape pattern combining all networks lead to two main and opposite stable states: either a landscape with a strong heterogeneity, or the emergence of a strongly dominant land use and almost no landscape heterogeneity. A comparison of scenarios has also revealed that effects on landscape heterogeneity and fragmentation are complex: (1) social network tend to improve heterogeneity of landscape, (2) global network has a significant impact on landscape metrics only when combined with local network and (3) local network has opposite effect on landscape pattern if combined with social network or global network. Finally, this study highlights that landscape complexity has to be considered through the multiplicity of pathways of landscape changes rather than through the resulting spatial pattern of landscape. In other words, multiple combinations of driving forces (social networks) may lead to similar landscapes as well as similar driving forces may guide to various landscapes changes.

\section{Acknowledgments}

We thank the MAPS network and the RNSC (French National Network on Complex Systems) for supporting and founding this study. We would like to thank D. Koopman from Vermont University USA and M. Kolb from CONABIO Mexico for the final revision and the three anonymous reviewers for their helpful comments and suggestions on earlier draft.

\section{Appendix A. Supplementary data}

Supplementary data related to this article can be found at http:// dx.doi.org/10.1016/j.envsoft.2012.11.003.

\section{References}

Baker, W.L., 1989. A review of models in landscape change. Landscape Ecology 2 (2), 111-133.

Baudry, J., Thenail, C., 2004. Interaction between farming systems, riparian zones, and landscape patterns: a case study in western France. Landscape and Urban Planning 67, 121-129.

Berger, T., 2001. Agent-based spatial models applied to agriculture: a simulation tool for technology diffusion, resource use changes and policy analysis. Agricultural Economics 25 (2/3), 245-260.

Bolte, J.P., Hulse, D.W., Gregory, S.V., Smith, C., 2007. Modeling biocomplexity actors, landscapes and alternative futures. Environmental Modelling \& Software 22 (5), 570-579.

Bretagnolle, A., Mathian, H., Pumain, D., Rozenblat, C., 2000. Long-term dynamics of European towns and cities: towards a spatial model of urban growth. Cybergeo 131, 1-19. http://www.cybergeo.eu/index566.html.

Brown, D.G., Page, S.E., Riolo, R., Rand, W., 2004. Agent-based and analytical modeling to evaluate the effectiveness of greenbelts. Environmental Modelling \& Software 19 (12), 1097-1109. http://dx.doi.org/10.1016/j.envsoft.2003.11.012.

Bryan, B.A., Crossman, N.D., King, D., Meyer, W.S., 2011. Landscape futures analysis: assessing the impacts of environmental targets under alternative spatial policy options and future scenarios. Environmental Modelling \& Software 26 (1), 83-91.

Burel, F., Baudry, J., 2003. Landscape Ecology: Concepts, Methods, and Applications, vol. XVI. Science Publishers, Enfield.

Bürgi, M., Hersperger, A.M., Schneeberger, N., 2004. Driving forces of landscape change-current and new directions. Landscape Ecology 19, 857-868.

Butler, S.J., Vickery, J.A., Norris, K., 2007. Farmland biodiversity and the footprint of agriculture. Science 315, 381-384.

Castellazzi, M.S., Wood, G.A., Burgess, P.J., Morris, J., Conrad, K.F., Perry, J.N., 2008. A systematic representation of crops rotations. Agriculture Systems 97 (1-2), 26-33.

Castellazzi, M.S., Matthews, J., Angevin, F., Sausse, C., Wood, G.A., Burgess, P.J., Brown, I., Conrad, K.F., Perry, J.N., 2010. Simulation scenarios of spatio-temporal arrangement of crops at the landscape scale. Environmental Modelling \& Software 25 (12), 1881-1889.

Daudé, E., 2004. Contributions of multi-agent systems for diffusion processes studies. Cybergeo 255, 1-16. http://www.cybergeo.eu/index566.html.

Daudé, E. Langlois, P., 2006. Comparaison de trois implémentations du modèle de Schelling. In: Amblard, F., Phan, D. (Eds.), Modélisation et simulation multi-agents application pour les Sciences de l'Homme et de la Société. Hermès, Paris, pp. 411441. http://www.univ-rouen.fr/MTG/Hermes\%202006\%20-\%20Ch17.pdf.

Dearing, J.A., Braimoh, A.K., Reenberg, A., Turner, B.L., van der Leeu, S., 2010. Complex land systems: the need for long time perspectives to assess their future. Ecology and Society 15 (4), 21. http://www.ecologyandsociety.org/vol15/ iss4/art21/.

Deffuant, G., Amblard, F., Weisbuch, G., Faure, T., 2002. How can extremism prevail? A study based on the relative agreement interaction model. Journal of Artificial Societies and Social Simulation 5 (4). http://jasss.soc.surrey.ac.uk/5/4/1.html.

Deke, O., 2008. Environmental Policy Instruments for Conserving Global Biodiversity. Springer Verlag, Berlin Heidelberg.

Etienne, M., 2006. Companion Modelling: a Tool for Dialog and Concertation in Biosphere Reserves. Biodiversity and Stakeholders: Concertation Itineraries, vol. 1. UNESCO-MAB, Biosphere Reserves, Technical Notes, pp. 44-52.

Gardner, R.H., Milne, B.T., Turner, M.G., O'Neill, R.V., 1987. Neutral models for the analysis of broad-scale pattern. Landscape Ecology 1, 19-28.

Gaucherel, C., Houet, T., 2009. Preface to the selected papers on spatially explicit landscape modelling: current practices and challenges. Ecological Modelling 220 (24), 3477-3480.

Gaucherel, C., Fleury, D., Auclair, D., Dreyfus, P., 2006. Neutral models for patchy landscapes. Ecological Modelling 197, 159-170.

Gereffi, G., Korzeniewicz, M., 1994. Commodity Chains and Global Capitalism. Praeger, Westport, Connecticut.

Gimblett, H.R., 2001. In: Integrating Geographic Information Systems and Agentbased Modelling Techniques for Simulating Social and Ecological Processes. Oxford University Press Inc, Coll. Santa Fe Institute in the Sciences of Complexity.

Gordon, L.J., Peterson, G.D., Bennett, E.M., 2008. Agricultural modifications of hydrological flows create ecological surprises. Trends in Ecology \& Evolution 23, 211-219.

Gotts, N.M., Polhill, J.G., 2009. When and how imitate your neighbours: lessons from and for FEARLUS. Journal of Artificial Societies and Social Simulation 12 (3).

Grimm, V., Berger, U., Bastiansen, F., Eliassen, S., Ginot, V., Giske, J., Goss-Custard, J. Grand, T., Heinz, S.K., Huse, G., Huth, A., Jepsen, J.U., Jørgensen, C., Mooij, W.M., Müller, B., Pe'er, G., Piou, C., Railsback, S.F., Robbins, A.M., Robbins, M.M., Rossmanith, E., Rüger, N., Strand, E., Souissi, S., Stillman, R.A., Vabø, R., Visser, U., DeAngelis, D.L., 2006. A standard protocol for describing individual-based and agent-based models. Ecological Modelling 198 (1-2), 115-126.

Grimm, V., Berger, U., DeAngelis, D.L., Polhill, J.G., Giske, J., Railsback, F., 2010. The ODD protocol: a review and first update. Ecological Modelling 221, 2760-2768.

Gustafson, E.J., 1998. Quantifying landscape spatial pattern: what is the state of the art? Ecosystems 1,143-156.

Houet, T., Loveland, T.R., Hubert-Moy, L., Napton, D., Gaucherel, C., Barnes, C., Sayler, K., 2010a. Exploring subtle land use and land cover changes: a framework based on future landscape studies. Landscape Ecology 25, 249-266. 
Houet, T., Verburg, P., Loveland, T.R., 2010b. Monitoring and modelling landscape dynamics. Landscape Ecology 25 (2), 163-167.

IMAGES, 2004. Final Report of the FAIR 3 2092-IMAGES Project: Improving Agrienvironmental Policies: a Simulation Approach to the Role of the Cognitive Properties of Farmers and Institutions. http://wwwlisc.clermont.cemagref.fr/ ImagesProject/FinalReport/final report V2last.pdf.

Kaufmann, P., Stagl, S., Franks, D.W., 2009. Simulating the diffusion of organic farming practices in two New EU Member States. Ecological Economics 68 (10), 2580-2593.

Kimura, M., 2002. The Use of Agent-based Models in Regional Science. PhD thesis, Cornell University.

Kristensen, S.P., Thenail, C., Kristensen, L., 2001. Farmers' involvement in landscape activities: an analysis of the relationship between farm location, farm characteristics and landscape changes in two study areas in Jutland, Denmark. Journal of Environmental Management 61, 301-318.

Lambin, E.F., Turner, B.L., Geist, H.J., Agbola, S.B., Angelsen, A., Bruce, J.W., Coomes, O.T., Dirzo, R., Fischer, G., Folke, C., George, P.S., Homewood, K., Imbernon, J., Leemans, R., Li, X.B., Moran, E.F., Mortimore, M., Ramakrishnan, P.S., Richards, J.F., Skanes, H., Steffen, W., Stone, G.D., Svedin, U., Veldkamp, T., Vogel, C., Xu, J.C., 2001. The causes of land use and land-cover change: moving beyond the myths. Global Environmental Change: Human and Policy Dimensions 11, 261-269.

Le, Q.B., Park, S.J., Vlek, P.L.G., 2010. Land Use Dynamic Simulator (LUDAS): a multiagent system model for simulating spatiotemporal dynamics of coupled human-landscape system. 2. Scenario-based application for impact assessment of land use policies. Ecological Informatics 5 (3), 203-221. http://dx.doi.org/10. 1016/j.ecoinf.2010.02.001.

Lindenmayer, D.B., Franklin, J.F., Fischer, J., 2006. General management principles and a checklist of strategies to guide forest biodiversity conservation. Biological Conservation 131 (3), 433-445.

Matthews, R., Gilbert, N., Roach, A., Polhill, J., Gotts, N., 2007. Agent-based land use models: a review of applications. Landscape Ecology 22, 1447-1459.

McAllister, R.R.J., Gordon, I.J., Stokes, C.J., 2005. KinModel: an Agent-Based Model of Rangeland Kinship Networks. International Congress on Modelling and Simulation (Modelling and Simulation Society of Australia and New Zealand, MODSIM), pp. 170-176, Available at: http://www.mssanz.org.au/modsim05/ papers/mcallister_1.pdf.

North, D.C., 1990. Institutions, Institutional Change, and Economic Performance. Cambridge University Press, Cambridge.

O’Neill, R.V., Krummel, J.R., Gardner, R.H., Sugihara, G., DeAngelis, D.L., Milne, B.T. Turner M.G. Zygmunt, B., Christensen, S.W., Dale, V.H., Graham, R.L. 1988. Indices of landscape pattern. Landscape Ecology 1, 153-162.

O’Neill, R.V., Gardner, R.H., Turner, M.G., 1992. A hierarchical neutral model for landscape analysis. Landscape Ecology 7, 55-61.

Parker, D.C., Berger, T., Manson, S.M. (Eds.), 2002. Agent-based Models of Land Use and Land-cover Change: Report and Review of an International Workshop, October 4-7, 2001, Irvine, California, USA, LUCC Report Series No. 6. Bloomington. Land Use and Cover Change Project. Available at: http://www.csiss. org/resources/maslucc/ABM-LUCC.pdf.

Parker, D.C., Manson, S.M., Janssen, M.A., Hoffmann, M.J., Deadman, P., 2003. Multiagent systems for the simulation of land use and land-cover change: a review. Annals of the Association of American Geographers 93, 314-337.

Parker, D.C., Entwisle, W., Moran, E., Rindfuss, R., Van Wey, L., Manson, S., Ahn, L., Deadman, P., Evans, T., Linderman, M., Mussavi, S.M., Malanson, G., 2008. Case studies, cross-site comparisons, and the challenge of generalization: comparing agent-based models of land use change in frontier regions. Journal of Land Use Science $3(1), 41-72$.

Parry, H.R., Topping, C.J., Kennedy, M.C., Boatman, N.D., Murray, A.W.A., 2012. A Bayesian sensitivity analysis applied to an agent-based model of bird population response to landscape change. Environmental Modelling \& Software, 12. http://dx.doi.org/10.1016/j.envsoft.2012.08.006.

Poiani, K.A. Richter, B.D. Anderson, M.G. Richter, H.E, 2000. Biodiversity conservation at multiple scales: functional sites, landscapes, and networks. BioScience 50 (2), 133-146.

Robinson, D.T., Brown, D.G., Parker, D.C., Schreinemachers, P., Janssen, M.A., Huigen, M., Wittmer, H., Gotts, N., Promburom, P., Irwin, E., Berger, T., Gatzweiler, F., Barnaud, C., 2007. Comparison of empirical methods for building agent based models in land use science. Journal of Land Use Science 2, 31-55.

Robinson, D.T., Sun, S., Hutchins, M., Riolo, R.L., Brown, D.G., Parker, D.C., Filatova, T., Currie, W.S., Kiger, S., 2012. Effects of land markets and land management on ecosystem function: a framework for modelling exurban land-change. Environmental Modelling \& Software. http://dx.doi.org/10.1016/ j.envsoft.2012.06.016.

Rouan, M., Kerbiriou, C., Levrel, H., Etienne, M., 2012. A co-modelling process of social and natural dynamics on the isle of Ouessant: sheep, turf and bikes. Environmental Modelling \& Software 25 (11), 1399-1412. http://dx.doi.org/10. 1016/j.envsoft.2009.10.010.

Saltiel, J., Bauder, J.W., Palakovich, S., 1994. Adoption of sustainable agricultural practices: diffusion, farm structure, and profitability. Rural Sociology 59 (2), 333-349.

Schmit, C., Rounsevell, M.D.A., 2006. Are agricultural land use patterns influenced by farmer imitation? Agriculture, Ecosystems and Environment 115 (1-4), $113-127$.

Schreinemachers, P., Berger, T., 2011. An agent-based simulation model of human environment interactions in agricultural systems. Environmental Modelling \& Software 26, 845-859.

Simon, C., Etienne, M., 2010. A companion modelling approach applied to forest management planning. Environmental Modelling \& Software 25 (11), 13711384.

Smajgl, A., Brown, D.G., Valbuena, D., Huigen, M.G.A., 2011. Empirical characterisation of agent behaviours in socio-ecological systems. Environmental Modelling \& Software 26 (7), 837-844. http://dx.doi.org/10.1016/j.envsoft.2011. 02.011 .

Treuil, J., Drogoul, A., Zucker, J., 2008. Modélisation et simulation à base d'agents, Exemples commentés, outils informatiques et questions théoriques. Dunod, Coll. Sciences Sup, Paris.

Urbani, D., 2006. Elaboration d'une approche hybride SMA-SIG pour la définition d'un système d'aide à la décision; application à la gestion de l'eau, Thèse de doctorat, Université de Corse Pasquale Paoli, http://tel.archives-ouvertes.fr/ docs/00/13/61/06/PDF/TheseURBANI.pdf.

Valbuena, D., Verburg, P., Bregt, A.K., Ligtenberg, A., 2010. An agent-based approach to model land use change at a regional scale. Landscape Ecology 25 (2), 185199. http://dx.doi.org/10.1007/s10980-009-9380-6.

Valente, T.W., 1995. Network Models of the Diffusion of Innovations. Hampton Press, Cresskill, New Jersey.

Veldkamp, A., Kok, K., De Koning, G.H.J., Schoorl, J.M., Sonneveld, M.P.W., Verburg, P., 2001. Multi-scale system approaches in agronomic research at the landscape level. Soil Tillage Resource 58, 129-140.

Wauters, E., Bielders, C., Poesen, J., Govers, G., Mathijs, E., 2010. Adoption of soil conservation practices in Belgium: an examination of the theory of planned behaviour in the agri-environmental domain. Land Use Policy 27, 86-94.

Wilensky, U., 1999. Netlogo. Center for Connected Learning and Computer-Based Modeling, Northwestern University, Evanston. http://ccl.northwestern.edu/ netlogo/.

Zimmerman, J.B., 2008. Le territoire dans l'analyse économique: proximité géographique et proximité organisée. Revue Française de Gestion 34 (184), $105-118$ 